\section{Еще раз о проблеме признания решений Европейского суда по правам человека в качестве источника российского права}

\section{Демичева 3.Б.}

Данная статья содержит авторский анализ так называемых «современных подходов к практике Европейского суда по правам человека, способствующих преодолению отставания отечественной юридической науки» ${ }^{1}$. Доктринальный спор о необходимости «модернизации основных положений юридического источниковедения» ${ }^{2}$ мог бы носить достаточно безобидный характер, не имей он серьезных практических последствий. Миной замедленного действия является признание отечественной юридической наукой правовых позиций Европейского суда по правам человека (ЕСПЧ) в качестве источника российского права. Дело в том, что этому противоречит даже учредительный договор данного контрольного механизма, а именно Конвенция о защите прав человека и основных свобод 1950 г., известная как «Европейская» (ЕКПЧ). Конвенция предельно четко обозначает субординационную деятельность Суда. А именно: ЕКПЧ наделяет Суд правом толкования правовых стандартов в области защиты прав человека (т.е. материальных договорных норм), содержащихся в ней ${ }^{3}$. Статья 46 (п. 1) Конвенции говорит лишь об обязательной силе окончательных постановлений, вынесенных Судом в отношении той или иной Высокой Договаривающейся Стороны по делам, в которых они являются сторонами ${ }^{4}$.

* Демичева Зинаида Борисовна - к.ю.н., третий секретарь Департамента общеевропейского сотрудничества МИД России.

${ }^{1}$ См.: Гаджиев Г. Имплементация решений Страсбургского суда // Сравнительное конституционное обозрение. № 1, 2006.

${ }^{2}$ Там же. С. 33 .

${ }^{3}$ Ст. 32 п.1 Конвенции: “The jurisdiction of the Court shall extend to all matters concerning the interpretation and application of the Convention and the protocols", "La compétence de la Cour s"étend à toutes les questions concernant l'interprétation et l'application de la Convention et de ses protocoles” - «В ведении Суда находятся все вопросы, касающиеся толкования и применения положений Конвенции и Протоколов к ней».

${ }^{4}$ См. также английский текст ст. 46 п. 1 Конвенции (The High Contracting Parties undertake to abide by the final judgment of the Court in any case to which they are parties) и французский (Les Hautes Parties contractantes s'engagent à se conformer aux arrêts définitifs de la Cour dans les litiges auxquels elles sont parties).
Пикантность ситуации в том, что текст этой статьи можно найти в новой действующей редакции Конвенции (вступила в силу 1 ноября 1998 г.), инкорпорировавшей Протокол № 115. Россия же, как известно, ратифицировала Конвенцию в марте 1998 г. Действительно, Федеральный закон Российской Федерации «О ратификации Конвенции о защите прав человека и основных свобод и Протоколов к ней» от 30 марта 1998 г. ссылается на текст статьи 46 не действующей в настоящее время редакции Конвенции:

«Российская Федерация в соответствии со статьей 46 Конвенции признает ірsо facto и без специального соглашения юрисдикцию Европейского суда по правам человека обязательной по вопросам толкования и применения Конвенции и Протоколов к ней в случаях предполагаемого нарушения Российской Федерацией положений этих договорных актов, когда предполагаемое нарушение имело место после их вступления в действие в отношении Российской Федерации».

В отсутствие такого текста статьи 46 Конвенции в новой редакции действующий упомянутый Федеральный закон лишается самого предмета отсылки. Мы оказываемся в парадоксальной ситуации: Федеральный закон прямо отсылает к статье, текст которой принципиально изменен. В данной ситуации целесообразно либо внести изменения в ФЗ о ратификации с учетом действующей редакции Конвенции, либо, оставляя данный текст ФЗ и реализуя т.н. «новые подходы», понимать, что основываются они на устаревшей международно-правовой норме, ныне не действующей.

Так, Председатель Конституционного Суда Российской Федерации В.Д. Зорькин в 2006 г. в своей статье «Роль Конституционного Суда Российской Федерации в реализации Конвенции о защите прав человека и основных свобод» пишет: «В заявлении, сделанном при ратификации Конвенции было сказано, что Россия «признает ipso facto и без специального соглашения юрисдикцию Европейского суда по правам человека обязательной по вопросам толкования и применения Конвенции и Протоколов к ней» ${ }^{6}$

${ }_{5}^{5}$ Конвенция о защите прав человека и основных свобод (STE/ETS № 5, заключена в г. Риме 4 ноября 1950 г.) (в редакции Протокола № 111998 г.) // Собрание законодательства Российской Федерации. 2001. № 2.

${ }_{6}$ В.Зорькин. Роль Конституционного Суда Российской Федерации в реализации Конвенции о защите прав человека и основных свобод// Сравнительное конституционное обозрение. № 1, 2006. С. 35. 
Но Россия никаких таких заявлений не делала. Это текст Федерального закона о ратификации Конвенции, в котором приводится существующее на тот момент положение международного договора. При этом в той же работе В.Д. Зорькин совершенно справедливо заявляет, ссылаясь на Конституцию Российской Федерации ${ }^{7}$, о приоритете международного договора Российской Федерации перед законом в случае их коллизии (ч. 4 ст. 15$)^{8}$.

Именно действующая редакция Конвенции о защите прав человека и основных свобод, включая статью 46, входит в правовую российскую систему в качестве источника права и является обязательной для всех субъектов российского права.

Скоро уже десять лет как нет старой редакции Конвенции, на формулировку статьи 46 которой ссылаются многие отечественные правоведы-реформаторы ${ }^{9}$. При этом, как правило, не делается никаких оговорок, предметно не рассматривается соотношение решений ЕСПЧ, носящих субсидиарный характер, с другими источниками права в англосаксонской и романо-германской правовых системах. А ведь признание прецедентного права в правовой системе России может серьезно ослабить юридическую силу Конституции, закона, привести к деформации последних посредством правоприменительной практики.

Аналогичные опасения высказываются и другими представителями романо-германской правовой группы государств - членов Совета Европы. Например, в Решении Федерального Конституционного Суда Федеративной Республики Германия от 19 октября 2004 г. «О принятии во внимание решений Европейского суда по правам человека национальными институтами, в частности германскими судами» ${ }^{10}$ сказано: «Быть связанным законом и правом (статья 20.3 Основного Закона (Grundgesetz - GG)) означает принимать во внимание гарантии

${ }^{7}$ Конституция России, принятая на всенародном референдуме 12 декабря 1993 г.

${ }^{8}$ В соответствии с ч. 4 ст. 15 Конституции Российской Федерации «международные договоры Российской Федерации являются составной частью ее правовой системы». Конституция Российской Федерации. Принята всенародным голосованием 12 декабря 1993 г. // Российская газета от 25 декабря 1993 г.

${ }^{9}$ См., например: А.Х. Абашидзе, Е.С. Алисиевич. Право Совета Европы. Конвенция о защите прав человека и основных свобод. М.: Международные отношения, 2007. С. 154. Е.С. Алисиевич. Правовые стандарты Европейского суда по правам человека/ /Россия и Совет Европы. Десятая юбилейная ежегодная научно-практическая конференция. Москва, 2006. С. 68.

${ }^{10}$ См. решение ЕСПЧ № 74969/01 от 26 февраля 2004 г. - «Гергюлю против ФРГ»"Görgülü versus Germany".
Европейской конвенции о защите прав человека и основных свобод и решения Европейского суда по правам человека в рамках методологически допустимого толкования закона. Как в случае непринятия во внимание решения ЕСПЧ, так и в случае механического «исполнения» такого решения в нарушение закона, имеющего приоритетную силу, могут быть нарушены основные права с учетом принципа верховенства закона.

Принимая во внимание решения ЕСПЧ, государственные органы в процессе правоприменения должны учитывать их последствия для национальной правовой системы ${ }^{11}$. Это особенно важно в тех случаях, когда соответствующая отрасль национального права является частью сбалансированной системы национального права, имеющей своей целью достижение баланса между различающимися основными правами» ${ }^{12}$.

Далее в п. 68 этого решения Суд указывает, что «обязанность принимать решения ЕСПЧ во внимание не только не ущемляет конституционно гарантированную независимость Верховного регионального суда, но и не заставляет суд бездумно исполнять решения ЕСПЧ. Вместе с тем Верховный земельный суд обязан соблюдать положения закона о ратификации и правовые нормы, которые включают в себя не только нормы гражданского права и соответствующие процессуальные нормы, но и положения Европейской конвенции о правах человека, которая имеет статус обычного федерального закона». ${ }^{13}$

${ }^{11}$ Выделено мною. - З.Д

${ }^{12}$ Citation: BVerfG, 2 BvR 1481/04 of October 14, 2004, paragraphs No. (1-72), http:// www.bverfg.de/entscheidungen/rs20041014_2bvr148104e.html

Параграф 68 упомянутого решения: "Being bound by statute and law (Article 20.3 of the Basic Law (Grundgesetz - GG)) includes taking into account the guarantees of the European Convention for the Protection of Human Rights and Fundamental Freedoms and the decisions of the European Court of Human Rights (ECHR) as part of a methodologically justifiable interpretation of the law. Both a failure to consider a decision of the ECHR and the "enforcement" of such a decision in a schematic way, in violation of prior-ranking law, may violate fundamental rights in conjunction with the principle of the rule of law.

In taking into account decisions of the ECHR, the state bodies must include the effects on the national legal system in their application of the law. This applies in particular when the relevant national law is a balanced partial system of domestic law that is intended to achieve an equilibrium between differing fundamental rights».

13 "The duty to take the decision into account neither adversely affects the Higher Regional Court's constitutionally guaranteed independence, nor does it force the court to enforce the ECHR decision without reflection. However, the Higher Regional Court is bound by statute and law, which includes not only civil law and the relevant procedural law, but also the European Convention on Human Rights, which has the status of an ordinary federal statute". 
Выдержки из Решения Конституционного Суда Германии приведены здесь лишь для того, чтобы подчеркнуть сложность и неоднозначность «новых российских подходов». Однако это недолжно толковаться как принижение значения постановлений ЕСПЧ, признающих не соответствующими Конвенции нормативные акты государств. Правовая доктрина, как отечественная, так и зарубежная, едина в том, что касается обязательности принятия во внимание прецедентной практики Европейского суда по правам человека.

Правда, здесь есть свои нюансы. Использование термина «прецедентная» в отношении судебной практики ЕСПЧ привело исследователей к дискуссии о правотворчестве Суда (т.е. создании правовых норм Судом). Учредительный акт ЕСПЧ - Конвенция о защите прав человека и основных свобод - наделяет Суд правом толкования положений Конвенции. В результате этой правоприменительной деятельности складываются правовые позиции ${ }^{14}$ - прецеденты толкования, которые не образуют каких-либо новых правовых норм или правовых стандартов.

Безусловно, ЕСПЧ должен оставаться единым европейским контрольных механизмом, следящим за соблюдением положений ЕКПЧ. В связи с этим особый интерес вызывает ситуация с Европейским сообществом (исходя из посылки, что до вступления в силу Договора, учреждающего Конституцию для Европы, Европейский союз не обладает международной правосубъектностью ${ }^{15}$ ). Европейское сообщество же обладает достаточно широкой международной правосубъектностью и уже является участником целого ряда двусторонних и многосторонних конвенций (в том числе Совета Европы ${ }^{16}$ ), состоит членом в некоторых международных организациях (например, во Всемирной торговой организации - ВТО). Однако начиная еще с конца 70-х годов прошлого века безрезультатно обсуждается вопрос о членстве $\mathrm{EC}^{17}$ в Совете Европы. Из-за того, что ЕС не является стороной Конвенции (хотя все 27 стран, в него входящие, являются участницами Конвенции), Европейский суд по правам человека не компетентен ratione personae рассматривать жалобы (как индивидуальные, так и межгосударственные), поданные против Европейского союза или Европейских сообществ ${ }^{18}$.

${ }^{14}$ См.: Б.Л.Зимненко. Решения Европейского суда по правам человека и правовая система Российской Федерации//Московский журнал международного права, № 2, 2004

${ }^{15} \mathrm{~B}$ правовой доктрине существует и др. точка зрения.

${ }^{16}$ Конвенции Совета Европы - http://conventions.coe.int, http://www.legal.coe.int

${ }^{17} \mathrm{EC} \mathrm{здесь} \mathrm{понимается} \mathrm{как} \mathrm{Европейское} \mathrm{сообщество.}$
Интересно проследить эволюцию развития отношений между ЕСПЧ (в то время еще существовали два контрольных органа Конвенции: Европейский суд по правам человека и Европейская Комиссия по правам человека) и Европейскими сообществами, начиная с самых ранних решений Суда 50 -х и 60-х годов прошлого века ${ }^{19}$.

В решении Комиссии по правам человека о приемлемости жалобы от 10 июня 1958 г. сказано, что в соответствии со ст. 1 ЕКПЧ государства-члены отвечают за необеспечение их органами прав и свобод человека вне зависимости от того, явились они следствием внутреннего права или обязательств, вытекающих из международных договоров, в которых они участвуют ${ }^{20}$.

В 70-х годах перед ЕСПЧ встал вопрос о возможности солидарной или коллективной ответственности государств - членов ЕС. В решении Комиссии по делу CFDT против Европейских сообществ от 10 июля 1978 г. сказано: «Так как жалоба подана против Европейских сообществ как таковых, которые не являются стороной ЕКПЧ (ст. 66 ЕКПЧ), то жалоба не может быть рассмотрена вследствие отсутствия ratione personae». И далее: «Что касается жалобы, поданной в ЕСПЧ против каждого государства - члена Европейских сообществ, то возникает вопрос, должны ли эти девять государств, которые в то же время являются Сторонами ЕКПЧ, отвечать за обжалуемый акт, принятый одним из институтов Европейских сообществ, в соответствии с Конвенцией $\rangle^{21}$.

Этот вопрос получил дальнейшее развитие в решении, принятом Комиссией 19 января 1989 г. (не опубликовано) по делу Дюфай против Европейских сообществ, и субсидиарно, против коллективной и индивидуальной ответственности их государств-членов. «Так как жалоба подана против государств - членов Европейских сообществ, которые в то же время являются сторонами Конвенции, возникает воп${ }_{18}$ Francoise Tulkens, Juge a la Cour europeene des droits de l'homme, Strasbourg,extraordinaire a l'Universite de Louvain. L'Union europeenne devant la Cour europeenne des droits de l'homme// Revue Universelle des droits de l'homme, 2000, Vol. 12 № $1-2$.

${ }^{19}$ Florence Benoit-Rohmer, Professeur a l'Universite Robert Schuman, Doyen de la Faculte de droits, Strasbourg. L'adhesion de l'Union a la Convention europeenne des droits de l'homme.//Revue Universelle des droits de l'homme, 2000, Vol. 12, № 12.

${ }^{20}$ Requete №233/56, Annuaire 2, p. 257.

${ }^{21}$ Requete №8030/77, D.R.13, p. 231 et s. Решение Комиссии по правам человека о приемлемости жалобы №8030/77 «СFDT против Европейских сообществ» от 10 июля 1978 г. 
poc, несет ли каждое из двенадцати государств - членов ЕС ответственность за акты, принятые каким-либо органом ЕС, в ЕСПЧ. Безусловно, компетенция Комиссии предусмотрена только в случае исчерпания всех внутренних средств защиты, и в соответствии с этим система защиты, предусмотренная в отношении права Европейских сообществ, аналогична защите, предусмотренной ст. 26 Конвенции. Следовательно, средства правовой защиты, предусмотренные правом Сообществ, аналогичны внутренним средствам правовой защиты в смысле вышеупомянутого положения Конвенции» ${ }^{22}$. В соответствии с этой аргументацией можно полагать, что Комиссия сочла, что в системе контроля, установленной ЕКПЧ, Суд ЕС должен рассматриваться как внутреннее средство правовой защиты.

В 2000 г., когда в ЕС входило только 15 стран, в ЕСПЧ находилась жалоба, поданная против пятнадцати государств - членов ЕС. В жалобе DSR-Senator Lines-GmbH против 15 стран-членов EC (application № 56672/00)23 заявитель утверждал, что был лишен права справедливого судебного разбирательства (ст. 6 и 13 Конвенции). Если бы Страсбургский суд создал прецедент, позволяющий оспаривать действия Сообществ посредством подачи жалобы против всех членов Европейского союза, это бы означало признание de facto присоединения Сообществ к Конвенции.

Появление Ниццского договора и Хартии Европейского союза об основных правах свидетельствует об углублении интеграции внутри Союза. Комиссар ЕС по вопросам правосудия и внутренних дел А. Виторино, член Президиума Конвента по разработке Хартии, заверял, что «Хартия и присоединение (к Европейской конвенции) не исключают друг друга, а напротив, могут осуществляться на базе подхода, существующего в государствах-членах, которые имеют собственный каталог прав в своих конституциях и в то же время участвуют в Европейской конвенции».

Во время подготовки Хартии Европейская комиссия отметила: «Существование Хартии не уменьшает интереса в присоединении (к Конвенции), так как оно установит эффективный внешний надзор за основными правами на уровне Союза». Однако Европейское сообщество так и не присоединилось к Конвенции. Конституция Евросоюза 2004 г. $^{24}$

${ }^{22}$ Requete №13539/88 (non publiee). См. RUDH 2000, p. 52.

${ }^{23}$ Requete №56672/00. HRLJ, 2000, p. 112.

${ }^{24}$ Официальное название - «Договор, учреждающий Конституцию для Европы». В силу не вступил. содержит следующую формулировку (п. 2, ст. I-9) о возможном присоединении Европейского союза к ЕКПЧ: «Союз присоединяется (англ. "shall accede") к Европейской конвенции о защите прав человека и основных свобод» $\rangle^{25}$.

Однако уже сейчас можно говорить о неизбежном дублировании, а может, и подмене функций ЕСПЧ Судом Европейских сообществ. Более того, существуют расхождения в практике двух Европейских наднациональных судов: ЕСПЧ и Суда Европейских сообществ в вопросах толкования прав человека и разрешения споров, возникающих в связи с нарушением этих прав.

Так, в постановлении от 4 февраля 2000 г. по делу C-17/98 Emesa Sugar Суд ЕС отклонил толкование Европейского суда по правам человека ст. 6 п. 1 Конвенции, данное им в деле Вермюлен против Бельгии, как неприменимое к процессуальным правилам судопроизводства в Суде $\mathrm{EC}^{26}$. В соответствии с этим толкованием право на состязательный процесс, гарантированное ст. 6 Конвенции, означает, что стороны процесса «вправе знакомиться со всеми доказательствами или замечаниями, приобщенными к делу, и оспаривать их; это относится и к заключениям, сделанным независимым представителем прокурорской службы, которые оказывают влияние на решение суда» (Вермюлен, пп. 31 и 35 судебного решения $\left.{ }^{27}\right)$. Оспорить в ЕСПЧ процессуальные правила Суда ЕС, а именно отсутствие возможности отвечать на заключение Генерального адвоката (право на состязательный процесс, нарушение ст. 6 п. 1 Конвенции), у заявителя права нет.

Вопрос о юридической силе постановлений ЕСПЧ на всем европейском пространстве представляет самый острый интерес как в правовом, так и в политическом плане. В настоящее время в соответствии с решениями Третьего саммита Совета Европы (май 2005 г.) подготовлен Меморандум о взаимопонимании между Советом Европы и Европейским союзом, призванный предложить пути реализации идеи создания Европы без разделительных линий. Меморандум был подпи-

${ }^{25}$ Treaty establishing a Constitution for Europe. European Communities, 2005. P. 19.

${ }^{26}$ Florence Benoit-Rohmer, Strasbourg.L'Affaire Emesa Sugar: l'institution de l'avocat general de la Cour de justice des Communautes europeennes a l'epreuve de la jurisprudence Vermeulen de la Cour europeenne des droits de l'homme.//Cahiers de droit europeen, 2001 numeros 3-4.

${ }^{27}$ Постановление Европейского суда по правам человека от 20 февраля 1996 г. по делу «Вермюлен против Бельгии»// Европейский суд по правам человека. Избранные решения. М., Норма, 2000. Т. 2, с. 174-182. 
сан в мае 2007 г. Решит ли он дилемму «двух Европ» - большой ${ }^{28}$ и малой ${ }^{29}$ - покажет время.

Once more on recognition of the case-law of the European Court of Human Rights as the source of the Russian legal system (Summary)

\section{Zinaida B. Demicheva*}

The purpose of the present article is to consider validity of "modern approaches to the case-law of the European Court of Human Rights as a source of the Russian legal system" forwarded by advocates of "an overcoming a lag of the domestic doctrine of international law".

The author of this article proceeds from the fact that even the constitutive treaty of the European Court of Human Rights - Convention for the Protection of Human Rights and Fundamental Freedoms (known as "European")-extends the jurisdiction of the Court to the matters concerning the interpretation and application of the Convention and the protocols (Article 32 p. 1). Article 46 (p. 1) demands from the participating states to abide and execute only the final judgments of the Court to which they are parties. However this wording contradicts the Russian ratification law, which invokes the older version of this article without amendments, introduced by Protocol No 11. Thus, there's collision between the said Russian Federal ratification law and corresponding provision of the effective text of the Convention.

Though it should also be stressed that the Constitution of the Russian Federation (Article 15 p. 4) determines that should an international treaty of Russia establish rules other than those established by law, the rules of the international treaty shall apply.

${ }^{28}$ В н.вр. СЕ объединяет 47 государств Европы.

${ }^{29}$ В н.вр. ЕС объединяет 27 государств Европы.

*Zinaida B. Demicheva-Ph.D. in Law, 3rd secretary of the European cooperation department of the Ministry of Foreign Affairs of the Russian Federation.
МЕЖДУНАРОДНОЕ ЭКОНОМИЧЕСКОЕ ПРАВО

\section{Комментарий к статье VI ГАТT: проблемы применения антидемпинговых мер в России и за рубежом}

Галичий C.A.*

\section{Введение. К истории вопроса}

Демпинг и антидемпинговая практика государств не случайно привлекают внимание юристов, в том числе юристов-международников ${ }^{1}$. Наиболее активно антидемпинговое законодательство изначально развивалось в США, зачастую к односторонней выгоде американских предприятий. В связи с противоречивой практикой проблематика антидемпингового правового режима в развитых странах мира была быстро интернационализирована.

По предложению представителей США специальные положения по демпингу в 1947 году были сформулированы в ст. VI Генерального соглашения по тарифам и торговле (ГАТТ-47). Неудивительно, что с тех пор международно-правовое регулирование антидемпингового процесса отражает англосаксонский правовой менталитет, прежде всего идеологию, заложенную в законодательство США².

Статья VI ГАТТ стала, таким образом, международно-правовым инструментом, с помощью которого сформировавшееся национальное антидемпинговое законодательство подверглось унификации. Текст ГАТТ, приложенный к уставу Всемирной торговой организации (ВТО),

${ }^{*}$ Галичий С.А.- -аспирант Всероссийской академии внешней торговли.

${ }^{1}$ См., например: Шумилов В.М. Международное экономическое право, Ростов-наДону, 2003. С. 322 и след.; Там же: Всемирная торговая организация: право и система, M., 2006. C. 78-104

${ }^{2}$ Dam K.W. The GATT: Law and International Economic Organization. Chicago, 1970. P. 172 . 